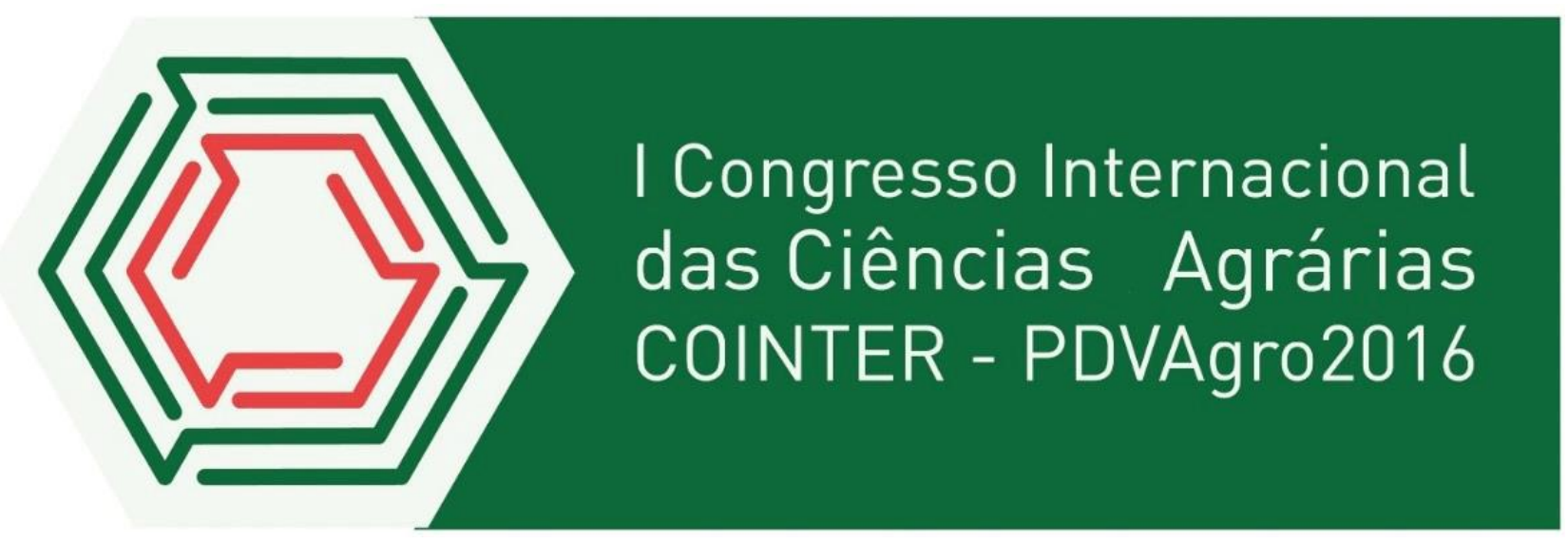

\title{
COMERCIALIZAÇÃO E DESTINO DE FRUTAS E HORTALIÇAS APÓS AS FEIRAS AGROECOLÓGICAS DE MUNICIPIOS PARAIBANOS
}

\author{
Apresentação: Pôster
}

Jairo Janailton Alves dos Santos ${ }^{1}$; Jordânia Araújo ${ }^{2}$; Vanessa da Costa Santos ${ }^{3}$; Flávio Gomes Fernandes $^{4}$; Raunira da Costa Araújo ${ }^{5}$

\section{Introdução}

As feiras livres são canais de comercialização de produtos da Agricultura Familiar que raramente recebem apoio de políticas públicas específicas ou são objetos de programas de desenvolvimento rural. Quando presentes, os programas estão marcados por um forte caráter produtivista, deixando em segundo plano a análise das categorias sociológicas envolvidas na atividade. Para RIBEIRO et al., (2005), tal fato expõe a invisibilidade econômica das atividades locais e certa marginalização da Agricultura Familiar nos programas de desenvolvimento dos municípios. Conforme o autor, são escassos os estudos sobre as feiras, sendo que a maior parte aborda somente os aspectos mercadológicos da atividade.

As feiras livres agroecológicas formam um instrumento socioeconômico de inclusão dos produtores rurais, permitindo que o mesmo possa estabelecer uma relação direta de comercialização com o consumidor, sem a necessidade de intermediários, dando assim a oportunidade de este

\footnotetext{
${ }^{1}$ Mestrando, Universidade Federal da Paraíba (UFPB) - Campus Bananeiras - PB, E-mail: jjasnp@hotmail.com

${ }^{2}$ Mestrando, Universidade Federal da Paraíba (UFPB) - Campus Bananeiras - PB, E-mail: jordania_1990@hotmail.com

${ }^{3}$ Tecnólogo em Agroecologia, IFPB - Campus Picuí, E-mail: nessacosta1995@hotmail.com

${ }^{4}$ Mestrando, Universidade Federal da Paraíba (UFPB) - Campus Bananeiras - PB, E-mail: flaviogomes473@gmail.com

${ }^{4}$ Professora, Universidade Federal da Paraíba (UFPB) - Campus Bananeiras - PB, E-mail arinuar@hotmail.com
} 
agregar valor a seu produto, fazendo com que o mesmo consiga ampliar sua margem de lucro (SILVA et al, 2006).

Um dos segmentos que têm merecido especial atenção é o dos alimentos orgânicos. Devido às características nutritivas e de salubridade que estes alimentos possuem, a sua procura tem sido cada vez maior. Outro importante motivo é a contribuição ao bem-estar de agricultores familiares, que atualmente vem se beneficiando direta ou indiretamente com a comercialização de alimentos produzidos de modo orgânico (NEUTZLING, et al. 2009).

A palavra qualidade na produção orgânica tornou-se sinônimo de alimentação saudável. Ela orienta os sistemas de produção para uma agricultura sustentável e ecologicamente segura, assim obtém produtos inócuos (livres de patógenos) e contribui para a segurança alimentar (VALENT, et al., 2014).

Sobre o questionário, Chizzotti (1991) indica que este instrumento é um conjunto de questões pré-elaboradas, sistemática e sequencialmente dispostas em itens que constituem o tema da pesquisa, com o objetivo de suscitar das informantes respostas por escrito ou verbalmente sobre o assunto que os informantes saibam opinar ou informa. De acordo com Gil (2007), a entrevista estruturada se desenvolve a partir de uma relação fixa de perguntas.

O objetivo do trabalho foi verificar o destino dado aos principais produtos comercializados nas feiras agroecológicas dos munícipios de Bananeiras, Remígio e Esperança com os produtos remanescentes das feiras.

Metodologia

O presente trabalho foi realizado nas feiras livres de três municípios da Paraíba (Figura 1) que comercializam produtos agroecológicos, sendo eles: Remígio, Solânea e Bananeiras. As atividades de Remígio e Esperança ocorrem às sextas-feiras pelo período da manhã; a de Bananeiras é realizada às quartas-feiras pela manhã. 
Figura 1: Localização do Estado da Paraíba no mapa do Brasil.

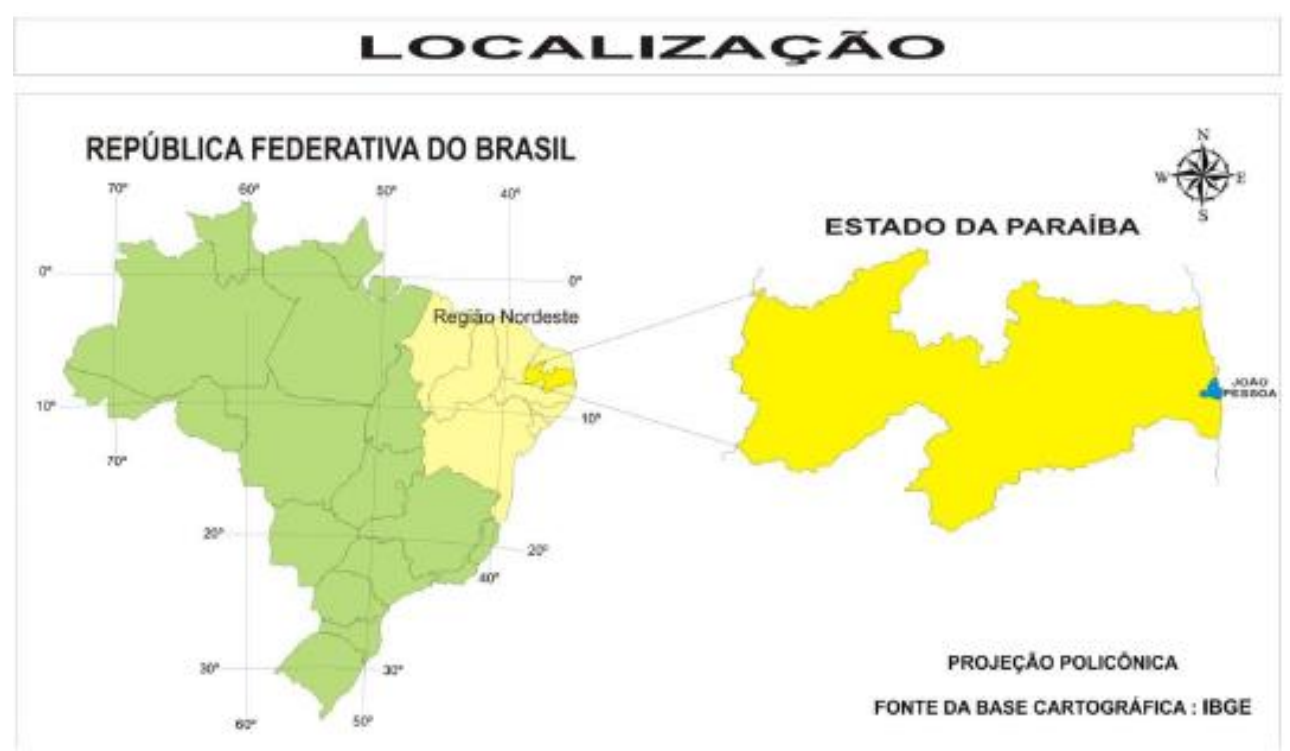

Fonte: IBGE

A pesquisa foi realizada no mês de julho utilizando-se questionários que foram elaborados baseados em Verdejo (2006). Foram aplicados questionários com os agricultores que, especificamente, produziam e comercializavam nas feiras dos municípios. As perguntas contidas foram referentes aos principais produtos comercializadas e ao destino dado após as feiras.

Com os dados coletados foram analisados isoladamente para cada município e posteriormente feita a tabulação cruzada das variáveis entre os municípios a partir do Excel.

Para esta pesquisa foram aplicados os questionários para $100 \%$ dos feirantes, visto que o número de entrevistados era pequeno. $\mathrm{Na}$ cidade de Bananeiras, a feira livre agroecológica apresenta apenas cinco barracas, enquanto que em Esperança possuem oito e em Remígio sete.

Resultados e Discussão

As feiras livres são ambientes democráticos de comercialização, principalmente, de frutas e hortaliças onde é bastante procurada pelos consumidores por apresentarem alimentos frescos e de boa qualidade aparente. Durante esta pesquisa foi visitado as feiras agroecológicas de Bananeiras, Remígio e Esperança. Assim como Santos et al. (2015), os principais produtos encontrados a venda nas feiras foram frutas, legumes e verduras. De acordo com o autor, estes produtos requerem alguns cuidados especiais para sua comercialização. Alguns frutos, bem como as hortaliças podem ser comercializados a temperatura ambiente. 
A comercialização das hortaliças (Figura 1) na feira de Esperança mostrou-se presente em $100 \%$ das barracas, assim como na feira de Bananeiras. Estes vegetais de ciclo curto são mais fáceis de serem produzidos mesmo tendo uma maior necessidade de irrigações. No entanto, o município de Remígio obteve $\mathbf{8 5 , 7 1 \%}$ da comercialização das hortaliças. Esse resultado se caracteriza pelo município se encontrar em uma área que apresentam índices pluviométricos diferentes dos outros dois municípios.

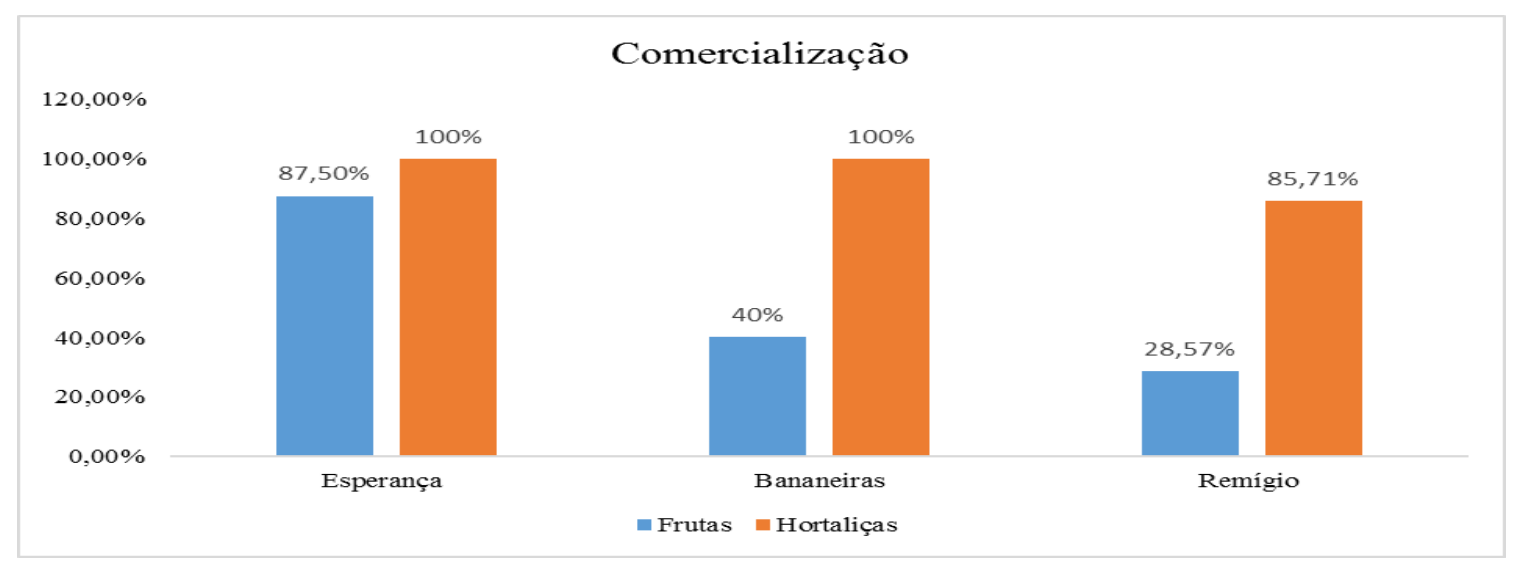

Figura 2: Percentual de frutas e hortaliças comercializadas nas feiras agroecológicas de Bananeiras, Esperança e Remígio.

Em relação às frutas o percentual de comercialização foi menor do que hortaliça nos três municípios, sendo estes produtos mais demorados de serem produzidos, apresentarem épocas especificas para as colheitas, ainda mais quando não se utiliza de irrigações diretas durante todo o ano. Dentre os municípios pesquisados o de Esperança apresentou maior percentual de barracas comercializando as frutas, seguidas pelo município de Bananeiras e Remígio.

No Brasil, a maioria da comercialização de produtos orgânicos, principalmente hortaliças, é realizada por meio da venda direta ou em feiras. A qualidade do alimento é atribuída à ausência de produtos químicos, porém, cada pessoa associa qualidade a um atributo específico (VALENT, et al. 2014).

Para garantir esta melhor aparencia dos produtos, os que apresentam variação em relação a este parâmetro, são descartados pelos feirantes. Após as feiras, os produtos excedentes e os que apresentaram variação de aparência seguem caminhos semelhantes em ambas as feiras. Os produtos que apresentam boa aparência após a feira agroecológica de Esperança seguem para doação, consumo familiar ou, em alguns casos, são destinados a feira convencional que é realizada no dia 
posterior a feira agroecológica (Figura 3). O pouco de material que é descartado por não apresentar uma boa qualidade visual, é destinado a arroçoamento animal.

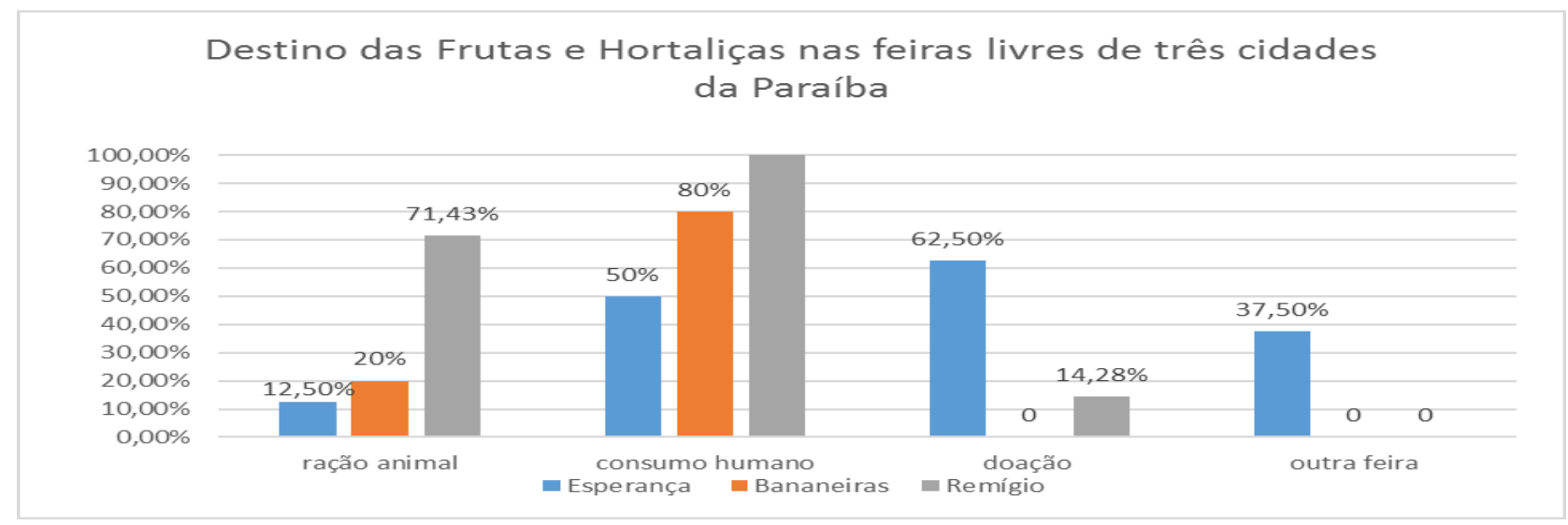

Figura 3: Destino dos produtos excedentes das feiras agroecológicas de Bananeiras, Esperança e Remígio.

Na cidade de Remígio, o principal destino do excedente foi para alimentação humana a partir de troca com outros feirantes ou realizada a doação para a Casa do Idoso da cidade. Assim como em Esperança, os materiais que não apresentavam características que podessem ser consumidos, foram destinados para ração para os animais.

A feira de Bananeiras por ser menor apresentava apenas dois destinos para as sobras da comercialização, sendo utilizados pela grande maioria para o consumo familiar dos produtores ou até fornecidos a algum dos vizinhos. As frutas e hortaliças murchas ou com algumas folhas secas eram destinadas a alimentação animal.

Alimentos com características de qualidade e segurança são as novas exigências requeridas pelos consumidores. Essas reivindicações obrigam produtores a buscarem alternativas de produção para se adaptarem às mudanças que estão ocorrendo no sistema agroalimentar. "O consumidor vem atuando de forma decisiva neste cenário de mudanças, exigindo não só alimentos com atributos gastronômicos e nutricionais, mas com qualidade e segurança a eles associadas” (SPERS, 2000). Conclusões

Os feirantes sempre reaproveitam os produtos de alguma forma. Sendo assim, não existe desperdício dos produtos comercializados nas feiras agroecológicas pesquisadas.

\section{Referências Bibliográficas}

CHIZZOTTI, A. A Pesquisa em Ciências Humanas e Sociais. São Paulo: Cortez, 1991. 
NEUTZLING; D. M; CALLADO, A. L. C; GAMARRA, J. E. T; et al. CONSUMIDOR DE ALIMENTOS ORGÂNICOS: UM ESTUDO NA FEIRA DOS AGRICULTORES ECOLOGISTAS (FAE) DE PORTO ALEGRE. $48^{\circ}$ Congresso SOBER- Sociedade Brasileira de Economia, Administração e Sociologia Rural; Campo Grande - MS, 2009.

RIBEIRO, E. M., CASTRO, B. S.; SILVESTRE, L. H., et al. Programa de apoio às feiras e à Agricultura Familiar no Jequitinhonha mineiro. Agriculturas - v. 2 - n. 2 - junho de 2005.

SANTOS, V. DA C.; SILVA, R. DOS S.; SANTOS, J. J. A. DOS; et al. Feiras livres: origem e beneficiamento dos produtos vegetais comercializados. I Encontro de Extensão, Pesquisa e Inovação em Agroecologia. IFPB, Picuí - PB. 15 a 18 de dezembro de 2015. Anais... 2015.

SILVA, R. A. R. SILVA SOBRINHO, R. D. SANTOS, R. J. C. et al. DESENVOLVIMENTO DE AÇŐES PARA A MELHORIA DA FEIRA LIVRE DO MUNICÍPIO DE AREIA. $8^{\circ}$ seminário de pesquisa e extensão, Centro de Ciências Agrárias UFPB. 2006. Disponível em: $:<$ http://www.prac.ufpb.br/anais/IXEnex/extensao/documentos/anais/8.TRABALHO/8CCADCFSP EX01.pdf.> Acesso em agosto de 2016.

SPERS, E E. Qualidade e Segurança em Alimentos. In: In: ZYLBERSZTAJN, D.; NEVES, M. F. (Org.). Economia e Gestão dos Negócios Agroalimentares. São Paulo: Pioneira, 2000, p. 283-321.

VALENT, J. Z.; TISOTT, S. T.; SCHMIDT, V.; et al. Qualidade de produtos orgânicos: a percepção dos produtores de hortaliças de uma feira ecológica em Porto Alegre - RS. REGET - V. 18 n. 1 Set-Dez. 2014, p. 1072-1082.

VERDEJO, M. E. Diagnóstico rural participativo: guia prático DRP. Brasília: MDA / Secretaria da Agricultura Familiar, 2006. 